\title{
Phenotyping of Plants for Drought and Salt Tolerance Using Infra-Red Thermography
}

\author{
Taek-ryoun Kwon ${ }^{1}$, Kyung-hwan Kim ${ }^{1}$, Hae-Jin Yoon ${ }^{1}$, Seung-kon Lee ${ }^{1}$, Beom-ki Kim ${ }^{1}$, Zamin Shaheed Siddiqui ${ }^{2}$ \\ ${ }^{1}$ Department of Agricultural Biotechnology, The National Academy of Agricultural Sciences, Jeonju 54874, Korea \\ ${ }^{2}$ Stress Physiology Phenomic Center, Department of Botany, University of Karachi, Karachi 75270, Pakistan
}

\begin{abstract}
Drought and salinity are the major environmental constrains in global agricultural production. Plant breeding for the drought and salt tolerance needs a proper assessment procedure to overcome stress constrain. Fundamental understanding on the physiological nature of the plant tolerance provides valuable information for the genetically modified crop's development. Drought or salt stress induces several common physiological responses in plants such as water relation and photosynthetic capacitiy. It is because both stresses lead cellular dehydration in the plants, particularly, during the early phase of stress imposition. Drought and salinity decrease $\mathrm{CO}_{2}$ availability for photosynthesis via stomatal limitation as well as elevate leaf temperature due to partially closed stomata. In this scenario, stomatal regulation and plant water status are important aspects in abiotic stress environment. These physiological responses have a function to stabilize the temperature inside plant/leaf. Therefore phenotyping through an infra-red thermography (heat sensitive sensor), could be a useful tool in the selection of a tolerant genotypes. Infra-red thermography is a part of the electromagnetic spectrum which emits a certain amount of radiation as a function of their temperatures. In general, the plants which have less water, would have higher temperature and display more infra-red radiations. In abiotic stresses such as drought and salinity, plant water status is affected and varied from the sensitive to tolerant level. Infra-red images of plants are often linked with some of the physiological attributes to the tolerance. This review covers the limits, advantages, linkages, comparison and other prospectives of using thermal imagaes in modern phenotyping techniques.
\end{abstract}

Keywords Drought, Infra-red thermography, Phenomics, Physiological traits, Salinity

\section{INTRODUCTION}

It is largely known that drought and salinity are main environmental constrains confronting global agricultural production. These two adverse environmental stresses affect over more than 10 percent arable land in the world (Bray et al. 2000). Drought and salinity cause detrimental decline of agricultural productivity causing more than $50 \%$ reduction of regular yield in globally important crops. Thus, the improvement of drought and salt tolerance in crop plants is an important goal for crop breeding.

Fundamental understanding on the nature of the tolerance is prerequisite step in the development of crop plants for drought and salt tolerances. Plant tolerance against these stresses can be obtained from stacking multiple physiological traits and several metabolic processes in the presence of adverse drought and salinity consequences, leading challenges to determine the fundamental process attributing for the tolerance (Flowers 2004).

Drought or salt stress prompts several common responses in plants such as relative water content, osmotic potential, quantum yield efficiency etc (Munns 2002; Bartels and Sunkar 2005; Chaves et al. 2009). Both stresses lead cellular dehydration in the plants, particularly, during the early phase of stress imposition which results in osmotic imbalance and movement of cytoplasmic water into apoplatic space. Further changes in metabolic processes, decreasing photosynthesis activity and rising plant hormone like absicic acid were also common in plants when subject to drought and salt stresses (Siddiqui et al. 2014a).

Plants adapt to adversity of drought and salinity by

Received October 7, 2015; Revised November 17, 2015; Accepted November 19, 2015; Published November 30, 2015

*Comesponding author Taek-ryoun Kwon, trkwon@Korea.kr, Tel: +82-63-238-4661, Fax: +82-63-238-4654 
several physiological adjustment such as osmotic adjustment, water and photosynthetic control, oxidative protection, molecular signaling and gene regulation (Silveira et al. 2012). However, some adaptive responses of plants to those stresses are stress-dependent. For instance, salt tolerance in plants operates specific mechanisms such as ionic homeostasis, nutritional balance, ion-specific signaling and gene expression. For drought tolerance, plants triggers specific signaling and gene expression to drought condition.

In photosynthesis, quantum efficiency of photosystem II is a primary physiological response to abiotic stress (Chaves 1991; Munns et al. 2006; Siddiqui et al. 2014b). These stresses decrease CO2 availability for photosynthesis via stomatal limitation (Flexas et al. 2007) and photosynthetic efficiency (Lawlor and Cornic 2002) via non-stomatal limitation. Plants also have complex processes of photosynthesis under drought and salt stresses (Chaves et al. 2009). Photosynthetic activities of stress-imposed plants depend on positions of leaves and stages of plant development. Moreover, the intensity and duration of the stresses influence the photosynthetic activity of plants.

Hence, it is important to understand the physiological mechanisms of tolerance regarding stress at whole plant level (Munns 1993). In saline environment, salt-induced reduction of plant growth is predominantly caused by osmotic stress at first short-term stress conditions (Munns et al. 2002), which is a similar response caused by drought. After the first phase, the second phase reduction of plant growth is predominantly occured by ion toxicity, which appears due to excessive toxic ion accumulation especially in the mature leaves, causing premature senescence and less photosynthetic ability. Plant tolerance against the stresses at whole plant level can be defined as maintaining ability of growth and metabolic process under the adverse stress conditions (Munns and Tester 2008).

There were considerable improvements for salt tolerance in crop plants such as rice, barley, maize, pear millet and so on, mainly through visual assessments of stressed plants in breeding program (Ashraf and Wu 1994). However, the physiological / biochemical mechanism underlying the phenotypic tolerance was not clear especially in the consideration as selection criteria. Thus special efforts have been made to develop reliable physiological / biochemical parameters for assessing the drought and salt tolerances.

Recently, high-throughput phenotyping approaches based on the parameters of the tolerance-related physiology and biochemistry have been emerged as a powerful methodology for the screening of drought and salt tolerances. A new approach comes from a theoretical background of 'Phenomics', which can be defined roughly as assessment of physiological and biochemical traits with camera's images taken at various light spectrums including RGB (Red, Green and Blue), infra-red, near infra-red, hyper-spectral spectrum and chlorophyll fluorescence (Lee et al. 2011). Honsdorf et al. (2014) successfully applied a high-throughput phenotyping to identify drought tolerance in wild barley introgression lines. Likewise, other scientists expanded the application of Infra-red thermography as a high-throughput phenotyping tool to field, indicating a possible screening for not only abiotic-stress tolerance but also biotic-stress tolerance (Prashar and Jones 2014). This review focuses on a screening of drought and salt tolerance of plants using infra-red thermography together with a few physiological traits. Bioassay of transgenic plant against drought stress in the field is always a problematic in particular. In this situation, bioassay of transgenic plant with infra-red camera can be useful tool to select drought tolerant genotypes in less time with key physiological traits.

\section{Principles of infra-red (IR) themography to evaluate salt and drought tolerances}

High-throughput phenotyping through an infra-red thermography (heat sensitive sensor) is based on the heat produced in stressed plant (Munns et al. 2010). Working with IR, it is possible to follow the progress of stressed plant over time quantitatively through combination of careful image capture, image analysis and color classification. In assessment of stressed plants, IR thermal sensing can provide rapid, vast and effective phenotyping but it has to be adopted certain principles. For instance, infra-red thermography is a part of the electromagnetic spectrum which emits a certain amount of radiation as a function of their temperatures.

Generally, plants would display higher temperature 
when they have less water; the more infra-red radiation is emitted. A special camera like IR can detect this radiation in a way similar to the way an ordinary camera detects visible light. It works well in total darkness because ambient light level does not matter. Infra-red thermal images tend to have a single color channel because the camera commonly uses an image sensor that does not differentiate wavelengths of infra-red radiation.

For use in temperature measurement, the brightest (warmest) parts of the images are typically colored white, intermediate temperatures reds and yellows, and the dimmest (coolest) parts black. It is totally dependent on the adjustment of colour scheme. A scale should be shown next to a false color image to relevant colors to a certain temperature. Their resolution is considerably lower than that of optical cameras, mostly in between $160 \times 120$ or $320 \times 240$ pixels, although some advanced cameras can also achieve a better resolution of $1280 \times 1024$ pixels. In un-cooled detectors, the temperature differences at the sensor pixels are $1{ }^{\circ} \mathrm{C}$. The pixel response time is also fairly slow, at the range of tens of milliseconds. Camera sensitivity is as fine as $<0.02^{\circ} \mathrm{C}$ for outstanding image quality and thermal patterns. Temperature range calibration of IR camera is up to $2,000^{\circ} \mathrm{C}$ for measuring the hottest objectives.

IR camera usually allows sensing of early heat gene- ration in stressed plant or plant organ, especially, leaf. In abiotic stresses such as drought and salinity, plant water status is affected and varied from the sensitive to tolerant level (Fig. 1). It was proved that cool parts of the stress tolerant plant indicate less heat compared to warm parts. Water status of leaf is reflected heat generation that can be detected and distinguished by IR camera using software under controlled environment. Stress-induced heat generation could be expressed as pattern of colour and average plant / leaf temperature. Stress sensitive wild-type plant showed less blue appearance compared to did stress tolerant transgenic plants. Similarly, root images of salt treated plant appeared as less blue as the concentration of the salt increased.

Plants with same genetic background may have different phenotypes, depending on the growing habitat. In last few decades, conventional screening based on visual assessment and physiological trait analysis has been declined due to hard, time consuming and destructive nature. However, latest development of high-throughput imaging systems and their computation allow modern, fast and nondestructive phenotyping in plant research. High-throughput phenotyping techniques using IR thermography can not only be useful to save time for screening of tolerance but also provide better coverage and non-destructive in nature.

\section{IR imager for Salt and Drought Stress Phenotyping}

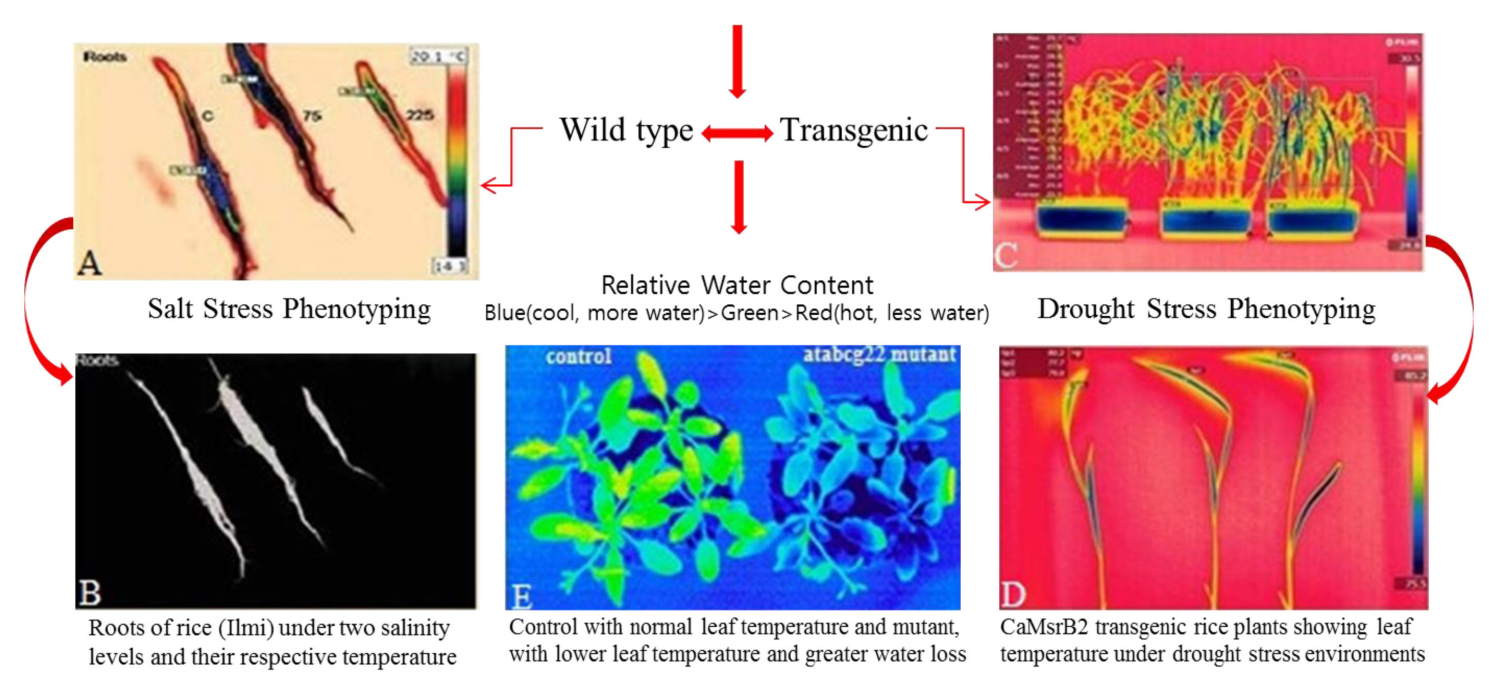

Fig. 1. Relationship between IR image's colour and water status in rice plants, especially, for the phenotyping for drought and salt tolerance. Image A, B, C and D (Siddiqui et al. 2014) E (Kuromori et al. 2011). 
Modern technology in phenomics research accelerates the process for selecting plant genotypes that perform better in the drought or salt affected field. Multiple physiological traits like stomatal conductance, osmotic potential, darkadapted quantum yield $\left(F_{v} / F_{m}\right.$ ratio) and biomass allocation were frequently used in low-throughput phenotyping for the selection of tolerant traits (Davies et al. 2005; Burke et al. 2006; Siddiqui et al. 2008; Munns et al. 2010; Richards et al. 2010; Siddiqui 2013).

\section{Phenotyping of transgenic plants for drought tolerance with IR images}

Drought is a main constraint among the abiotic stresses that occur in rain fed region. Climate extreme such as drought continues to hinder the ecosystem and agriculture of the region. Plant species have adapted to enhance their ability to tolerate abiotic stress through physiological adjustments (Siddiqui et al. 2014b).

Many research articles have forwarded to elucidate the response mechanisms of the plant against stress and their tolerance. Many transgenic plants have been developed to show drought resistance using modern biotechnology (Sharma and Gills 1994; Kumar and Kumar 1996; Shinozaki and Yamaguchi-Shinozaki 2000; Munns 2002; Siddiqui 2013; Siddiqui et al. 2014b). Bioassay of transgenic plant against drought stress in the field is always a problematic in particular because of complexity of environments and multiple traits. In this situation, bioassay of transgenic plant with IR camera can be a useful tool to find out drought tolerant genotypes in less time with substantial coverage. Foremost, IR thermography works on heat production and measure as temperature difference among the tested plants. IR thermograpies of plants are often linked with some of the physiological attributes to the tolerance. For instance, in a study of CaMsrB2 transgenic rice plant, thermal images of drought-tolerant transgenic genotypes and their wild types showed substantial difference in their thermal images (Fig. 2). The transgenic lines with drought tolerant gene had lower plant and leaf temperatures as compared to that of their wild-type plants.

Siddiqui et al. (2014) observed that in drought stress, CaMsrB2 expressing transgenic rice genotypes differed from its wild-type geneotypes in average plant temperature. The stress-induced changes of plant temperature have a significant relationship with the physiological traits of plants such as osmotic potential, RWC and stomatal conductance (Table 1). Significant negative correlations were found between average plant temperature and RWC $(\mathrm{r}=-0.905)$.

It was reported that forward-looking infra-red (IR) thermal images of stressed plants showed considerable differences in leaf temperatures of both transgenic lines as compared to the wild type under the drought stress (Siddiqui et al. 2014b). In a drought environment, leaf temperature of plant is an immediate indicator of internal water status. IR thermal sensing of drought imposed plants provided immediate indication for responses of plant against drought (Munns 2002; Sirault et al. 2009). There-

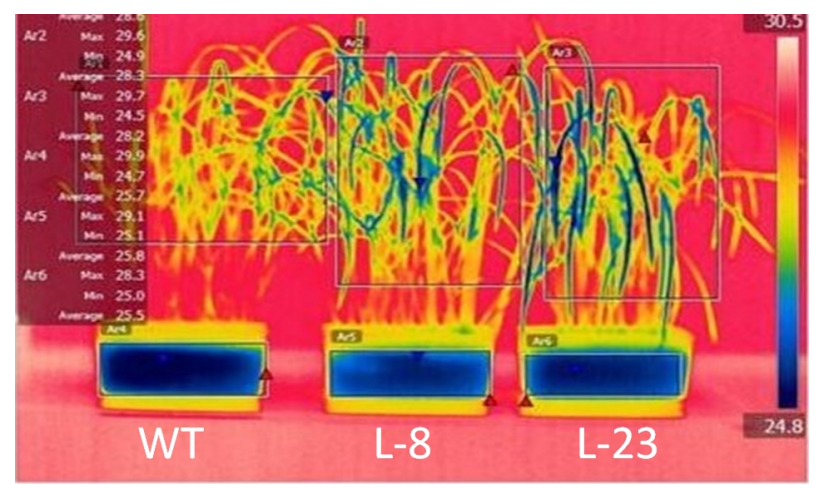

Fig. 2. IR image of $C a M s r B 2$ transgenic rice plants in drought expressing different leaf temperature as compare to their wild type (Siddiqui et al. 2014b). L-8 and L-23 are transgenic lines with the overexpressed drought tolerant gene, CaMsrB2. WT is their wild type. 
Table 1. Average leaf temperature and their correlation with some physiological traits under drought stress. Seedlings of CaMsrB2 expressing transgenic lines and its wildtype were imposed by drought stress via withholding water prior to measure those physiological traits (Siddiqui et al. 2014). Correlations were calculated between plant tempertature and their physiological data.

\begin{tabular}{lcccc}
\hline \hline Genotypes & Temperature ${ }^{\circ} \mathrm{C}$ & Osmotic Potential (bar) & RWC (\%) & $\begin{array}{c}\text { Stomatal Conductance } \\
\left(\mathrm{mmole} \mathrm{m}^{-2} \mathrm{~s}^{-1}\right)\end{array}$ \\
\hline WT & $27.80 \pm 0.12$ & $1.2 \pm 0.32$ & $40 \pm 3.22$ & $8.00 \pm 3.22$ \\
Line-8 & $27.27 \pm 0.13$ & $3.6 \pm 0.33$ & $54 \pm 4.33$ & $38.2 \pm 4.33$ \\
Line-23 & $27.07 \pm 0.12$ & $6.9 \pm 0.25$ & $68 \pm 6.52$ & $120 \pm 17.95$ \\
r & & $\mathbf{- 0 . 8 5}$ & $\mathbf{- 0 . 9 0 5}$ & $\mathbf{- 0 . 7 0 4}$ \\
\hline
\end{tabular}

Similar alphabet on each values represent non-significant at $P=0.01) \mathrm{r}=$ Correlation values Camera Model FLIR 620SC, software ThermaCAM.

Table 2. Average leaf temperature, relative water content (RWC) and stomatal conductance of rice plants under various salinity. Seedlings of rice genotypes, cvs. 'Dongjin' and 'Ilmi', were imposed by several $\mathrm{NaCl}$ salinity prior to measure those physiological traits using a protocol mentioned in Siddiqui et al. (2014b). Correlations were calculated between salinity and physiological changes.

\begin{tabular}{|c|c|c|c|}
\hline $\mathrm{NaCl} \mathrm{mM}$ & Temperature ${ }^{\circ} \mathrm{C}$ & RWC (\%) & Stomatal conductance (mmole $\mathrm{m}^{-2} \mathrm{~s}^{-1}$ ) \\
\hline 0 & $27.9 \pm 0.12$ & $75.3 \pm 3.22$ & $140 \pm 7.55$ \\
\hline 75 & $28.5 \pm 0.13$ & $70.0 \pm 4.33$ & $115 \pm 3.15$ \\
\hline 150 & $29.4 \pm 0.12$ & $52.5 \pm 3.95$ & $50.0 \pm 2.88$ \\
\hline 225 & $30.4 \pm 0.15$ & $40.0 \pm 2.25$ & $30.0 \pm 1.15$ \\
\hline $\mathrm{r}$ & +0.88 & -0.85 & -0.62 \\
\hline
\end{tabular}

Leaf temperature were measured by ThermaCAM software FLIR SC 620.

fore, phenotyping using a IR thermography recognizes drought-tolerant plants traits with greater efficiency. In sensitive genotypes, temperatures of leaf and plant body increased in water-deficit environments. In droughttolerant plants, stomata plays a key role to maintain enough moisture inside the leaf and lower temperatures under water deficit condition (Munns 2002; Jones et al. 2009), as was seen in CaMsrB2 transgenic lines. Therefore RWC and stomatal conductance were found to be consistent with IR thermography under drought stress. There were successful cases applying IR thermography to screen drought tolerant genotypes in wheat breeding (Fischer et al. 1998; Reynolds et al. 1998; Brennan et al. 2007).

\section{Phenotyping of transgenic plants for salt tolerance with IR images}

Conventional assessment of salt-tolerant physiological traits is time consuming, laborious, and mostly destructive. For the selection of the salt-tolerant plants, both conventional low-throughput physiological approaches and modern high-throughput phenotyping approaches have been used. Scientists need to correlate these two approaches and to homogenize the protocol for examining adequate phenotypes under salt stress that might have some role in the regulation of plant temperature (Merlot et al. 2002; Jones et al. 2009; Collins et al. 2010; Munns et al. 2010). Stomatal regulation and plant water status are important aspects in the presence of salt stress. These physiological responses have a function to stabilize the temperatures of plant/leaf. That could be examined by infra-red thermography (Table 2).

Siddiqui et al. (2014b) found that Cvs. 'Donjin' and 'Ilmi' vaired in expression of IR thermography with the increment of salt stress. As salinity incresed, plants changed from blue color to green, then yellow and red. Salinity- induced changes of IR thermography were significantly correlated with relative water content (RWC) of the plants. Physiological parameter such as stomatal conductance, which are open being used for plant's tolerance assessment, was also correlated well with 
average IR thermograpy pattern (Siddiqui 2013). However, photosynthetic performance index and dark-adapted quantum yield were not significantly correlated with the results obtained by IR thermography. However, many studies have used $F_{v} / F_{m}$ ratio as an indicator for stress tolerance or sensitivity (Penuelas and Boada 2003). The reason behind this may be that IR sensing is based on heat generation of plant which is linked with water status rather than photosynthetic efficiency. Any variation in leaf temperature due to heat production can be detected by IR thermography. Obtaining IR thermography on plants should be taken under a controlled environment. It was reported that surrounding environment of the target plants would affect the IR thermography (Siddiqui et al. 2014a). Stomatal conductance, relative water content and dark-adapted quantum yield of plants are affected by salt stress and some of these physiological attributes are linked with the leaf temperature (Munns et al. 2010). Commonly, water loss from leaf needs a considerable amount of energy to convert each molecule of water from liquid to vapor. This energy is then taken away from the leaf in the evaporating water for cooling purpose (Jones et al. 2009). Thus, for a given environmental or stress condition, leaf transpiration is an important determinant of leaf temperature. In the case of stress caused by either salt or drought, an immediate plant response is a reduction in transpiration of leaves to reduce water loss, resulting in an increase in the leaf temperature (Woo et al. 2008; Munns et al. 2010). Moreover, Garrity and O’Toole (1994) have postulated that IR thermography could be used to determine leaf and canopy temperature as an indirect estimation of plant water status. Relationship between physiological parameters and IR images is based on the type and nature of stress and genotypes. For instance, tolerant genotypes uptake soil water efficiently by maintaining higher stomatal conductance and therefore can show cooler leaves (Jones et al. 2009; Berger et al. 2010; Lu et al. 2011). Further, Sirault et al. (2009) proposed that leaf temperature could be an indicator of stomatal conductance. Leaf temperature increased along with the increment of salinity. The ranking of the genotypes based on the growth and thermal IR measurements was consistent (Sirault et al. 2009; Munns et al. 2010).
Moreover, water status in a plant is highly sensitive to salinity and therefore it is dominant in determining plant responses to stress (Stepien and Klobus 2006). Dark-adapted quantum yield responses to salt stress environment is rather slow and can be detectable in a large tray experiment using very small seedlings (Woo et al. 2008; Jansen et al. 2009). Since some experiments were carried out using small trays, dark-adapted quantum yield might not produce significant changes in leaf temperature and thus it could not be detected by IR thermal images sensing. Therefore, based on the working principels of the IR camera, IR thermography may not be related to the photosynthetic performance of a plant under salinity. Meanwhile, plant temperature allows the indication of the degree of stress in a plant with clear relationship with relative water content and stomatal conductance. Under salt stress environment, plant temperature and water status are perhaps linked to soil water availability, leaf water potential, and stomatal conductance. IR thermography was proved to be related to soil- and plant-based measures of water stress. It was also observed that IR thermography can be potentially used for identifying the differences among various genotypes in variable plant irrigation and stress environment (Romano et al. 2011; Zia et al. 2011). However, sophisticated technology in the field needs to be developed in order to identify the best protocol to optimize the data accuracy. Correlation analysis between conventional low-throughtput and modern high-throughput phenotyping showed that stress-induced changes of plant or leaf temperature could be a useful tool to screen genotypes for target tolerance. A modern IR thermography techniques may offer less time consuming, non-destructive and mass bioassay for phenotyping of plant's salt tolerance.

\section{CONCLUDING REMARKS}

Drought and salinity are greater challenges that cut off agricultural production substantially all over the world. Crop breeding for drought and salt tolerance is economically realistic measure to tackle the global challenges stemming from the unfavorable environmental constrain in the agricultural productivity. In fact, first step towards 
Stress-free plant

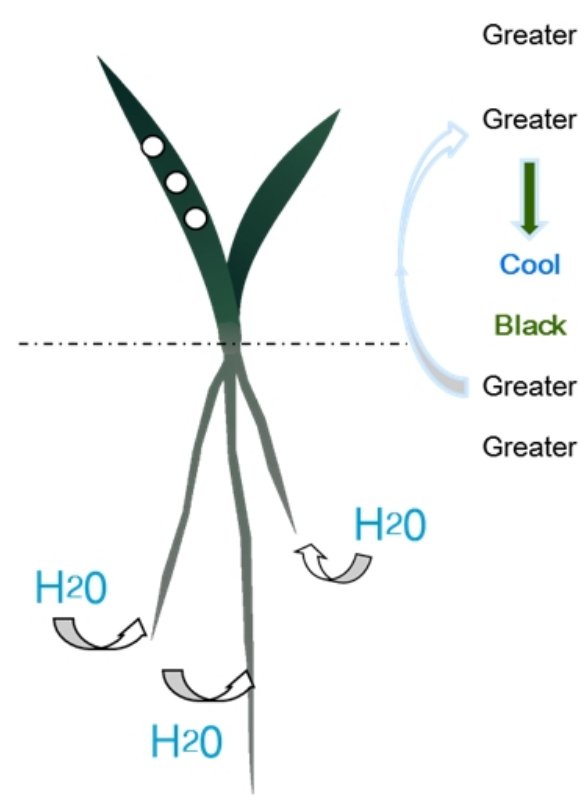

Drought / salt stressed plant

$\begin{array}{cc}\begin{array}{c}\text { Photosynthetic } \\ \text { activity } \\ \text { Stomatal } \\ \text { conductance }\end{array} & \text { Less } \\ & \\ \text { Leaf temperature } & \text { High } \\ \text { IR thermal image } & \text { Red } \\ \text { Water availability } & \text { Less } \\ \text { Water uptake } & \text { Less }\end{array}$

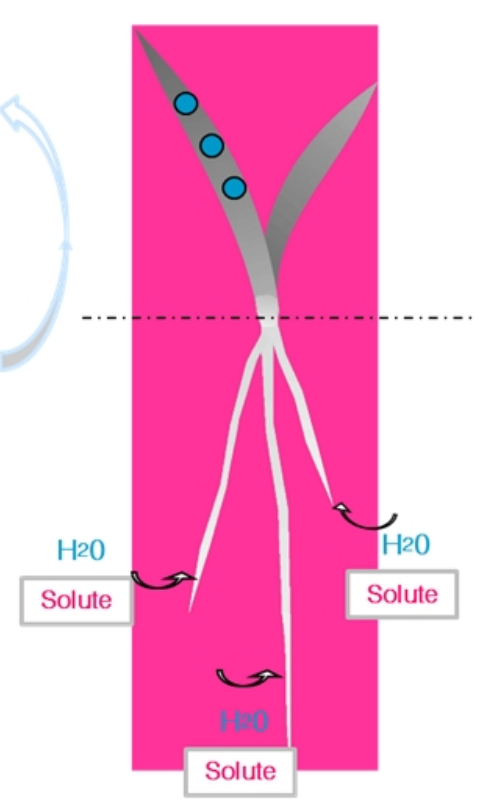

Fig. 3. Plants have different infra-red thermography depending on which they grown with or without drought/salt stress. The stressed plant has a limited water uptake in the presence of drought and salinity, resulting in less availability of tissue water. This dehydration causes plant to close stomata on leaf, leading an increment of temperature. Infra-red thermography can detect the stress-induced changes of temperature at last.

development of a practical stress-tolerant crop plant is to understand the fundamental mechanism working for the tolerance, which are based on the physiological and biochemical traits. Conventional plant breeding and modern biotechnologies have been applied to explore the tolerances of drought and salinity so far. However, a great challenge in the exploration of the stress-tolerant genotypes was to link between target genes, functioning for the tolerance, and relevant phenotypes, especially, at whole plant level.

So far many scientific works for the drought and salt tolerance adopted a destructive time-consuming approach to dig out the mechanism. So it was difficult to apply in the practical approaches to develop the tolerant genotypes, especially, in the agricultural field. Recently, converging various modern technologies like infra-red thermography, automated robotics, camera images, computational algorisms and biotechnologies creates unique approaches to help in the assessment of drought and salt tolerances in crop plants, providing with non-destructive mass measurements of certain physiological traits working for the tolerance. This review enlightened possible application of infra-red thermography as a tool to measure the drought and salt tolerances in plants along with stress-tolerant transgenic plants. A few reported cases of transgenic rice plants evaluation revealed that the infra-red thermography of the stressed plant successfully distinguished the difference between the tolerant lines and sensitive lines with great correlation with physiological traits like relative water content and stomatal conductance (Fig. 3). Tolerant genotypes showed cool infra-red thermal images of lower temperature with greater stomatal conductance and relative water contents in the presence of the stresses as compared with those of sensitive plants. Thus, it is suggested that high-throughput phenotyping with infra-red thermography can not only be a practical mass non-destructive measurement of drought and salt tolerance in plants but also be applied in the assessment of stress tolerant plants in a larger field area. 


\section{ACKNOWLEDGEMENTS}

This work was supported by grants from the National Institute of Agricultural Science (PJ01005702) and the National Center for GM Crops, Biogreen 21 program, RDA, Republic of Korea.

\section{REFERENCES}

Asfraf M, Wu L. 1994. Breeding for salinity tolerance in plants. Critical Reviews in Plant Sciences 13(1): 17-42.

Bartel D, Sunkar R. 2005. Drought and salt tolerance in plants. Critical Reviews in Plant Sciences 24: 23-58.

Berger B, Parent B, Tester M. 2010. High-throughput shoot imaging to study drought response. Journal of Experimental Botany 61: 3519-3528.

Bray EA, Bailey-Serres J, Weretilnyk E. 2000. Responses to abiotic stresses. In: Biochemistry and Molecular Biology of Plants. Gruissem W, Buchnnan B, and Jones R. eds. American Society of Plant Physiologists, Rockville, MD: 1158-1249.

Brennan JP, Condon AG, Van-Ginkel M, Reynolds MP. 2007. An economic assessment of the use of physiological selection for stomatal aperture-related traits in the CIMMYT wheat breeding program. Journal of Agricultural Sciences 145: 187-194.

Burke EJ, Brown SJ, Christidis N. 2006. Modeling the recent evolution of global drought and projections for the twenty-first century with the Hadley Centre climate model. Journal of Hydrometeorology 7: 1113-1125.

Chaves MM, Flexas J, Pinheiro C. 2009. Photosynthesis under drought and salt stress: regulation mechanisms from whole plant to cell. Annnals of Botany 103: 551-560.

Chaves MM. 1991. Effects of water deficits on carbon assimilation. Journal of Experimental Botany 42: 1-16.

Collins M, Fuentes S, Barlow EWR. 2010. Partial root zone drying and deficit irrigation increase stomatal sensitivity to vapour pressure deficit in anisohydric grapevines. Functional Plant Biology 37: 128-138.

Davies WJ, Kudoyarova G, Hartung W. 2005. Long-distance ABA signaling and its relation to other signaling pathways in the detection of soil drying and the mediation of the plant's response to drought. Journal of Plant Growth Regulators 24: 285-295.
Fischer RA, Rees D, Sayre KD, Lu ZM, Cordon AG, Saavedra AL. 1998. Wheat yield progress associated with higher stomatal conductance and photosynthetic rate and cooler canopies. Crop Science 38: 1467-1475.

Flexas J, Diaz-Espejo A, Galme’s J, Kaldenhoff R, Medrano H, Ribas-Carbo M. 2007. Rapid variations of mesophyll conductance in response to changes in $\mathrm{CO} 2$ concentration around leaves. Plant, Cell and Environment 30: 1284-1298.

Flowers TJ. 2004. Improving crop salt tolerance. Journal of Experimental Botany 55: 307-319.

Garrity DP, O’Toole JC. 1994. Screening rice for drought resistance at the reproductive phase. Field Crop Research 39: 99-110.

Honsdorf N, March TJ, Berger B, Tester M, Pillen K. 2014. High-throughput phenotyping to detect drought tolerance QTL in wild barley introgression lines. PLoS ONE 9(5): e97047. doi: 10.1371/journal.pone.0097047.

Jansen M, Gilmer F, Biskup B, Nagel KA, Rascher U, Fischbach A, Briem S, Dreissen G, Tittmann S, Braun S. 2009. Simultaneous measurement of leaf growth and chlorophyll fluorescence via GROWSCREEN FLUORO allows detection of stress tolerance in Arabidopsis thaliana and other rosette plants. Functional Plant Biology 36: 902-914.

Jones HG, Serraj R, Loveys BR, Xiong L, Wheaton A, Price AH. 2009. Thermal infra-red imaging of crop canopies for the remote diagnosis and quantification of plant responses to water stress in the field. Functional Plant Biology 36: 978-989.

Kumar V, Kumar D. 1996. Response of Indian mustard to saline water application at different growth stages. Trans. Indian Soc. Desert Technol. 15: 121-125.

Kuromori K, Sugimoto E, Shinozaki K. 2011. Arabidopsis mutants of AtABCG22, an ABC transporter gene, increase water transpiration and drought susceptibility. The Plant Journal 67: 885-894.

Lawlor DW, Cornic G. 2002. Photosynthetic carbon assimilation and associated metabolism in relation to water deficits in higher plants. Plant, Cell and Environment 25: 275-294.

Lee SK, Kwon TR, Seo EJ, Bae SC. 2011. Current statues of phenomics and its application for crop improvement: Imaging systems for high-throughput screening. Korean Plant Breeding Journal, 43: 165-172.

Lu Y, Hao Z, Xie C, Crossa J, Araus JL, Gao S, Vivek BS, 
Magorokosho C, Mugo S, Makumbi D, Taba S, Pan G, Li X, Rong T, Zhang S, Xua Y. 2011. Large-scale screening for maize drought resistance using multiple selection criteria evaluated under water stressed and well-watered environments. Field Crop Research 124: 37-45.

Merlot S, Mustilli AC, Genty B, North H, Lefevre V, Sotta B, Vavasseur A, Giraudat J. 2002. Use of infra-red thermal imaging to isolate Arabidopsis mutants defective in stomatal regulation. The Plant Journal 30: 601-609.

Munns R, James RA, Sirault XRR, Furbank RT, Jones HG. 2010. New phenotyping methods for screening wheat and barley for beneficial responses to water deficit. Journal of Experimental Botany 61: 3499-3507.

Munns R, Tester M. 2008. Mechanisms of salinity tolerance. Annual Review of Plant Biology 59: 651-681.

Munns R, James RA, Lauchli A. 2006. Approaches to increasing the salt tolerance of wheat and other cereals. Journal of Experimental Botany 57: 1025-1043.

Munns R. 2002. Comparative physiology of salt and water stress. Plant, Cell and Environment 25: 239-250.

Munns R. 1993. Physiological processes limiting plant growth in saline soil: some dogmas and hypotheses. Plant, Cell and Environment 16: 15-24.

Penuelas J, Boada M. 2003. A global change-induced biome shift in the Montseny mountains (NE Spain). Global Change Biology 9: 131-140.

Prashar A, Jones HG. 2014. Infra-red thermography as a high-throughput tool for field phenotyping. Agronomy 4: 397-417.

Reynolds MP, Singh RP, Ibrahim A, Ageeb OAA, LarqueSaavenra A, Quick JS. 1998. Evaluating physiological tools to complement empirical selection for wheat in warm environments. Euphytica 100: 84-95.

Richards RA, Rebetzke GJ, Watt M, Condon AG, Spielmeyer W, Dolferus R. 2010. Breeding for improved water productivity in temperature cereals: phenotyping, quantitative trait loci, markers and the selection environments. Functional Plant Biology 37: 85-97.

Romano G, Zia S, Spreer W, Sanchez C, Cairns J, Aeaus JL, Muller J. 2011. Use of thermography for screening genotypic water stress adaptation in tropical maize. Computer and Electronic in Agriculture 79: 61-74.

Sharma PC, Gill KC. 1994. Salinity-induced effect on biomass, yield, yield attributing characters and ionic contents in genotypes of Indian mustard. Indian Journal of Agricultural Science 64: 785-788.

Shinozaki K, Yamaguchi-Shinozaki K. 2000. Molecular response to dehydration and low temperature: differences and cross-talk between two stress signaling pathways. Current Opinion on Plant Biology 3: 217-223.

Siddiqui ZS, Cho JI, Park SH, Kwon TR, Ahn BO, Lee GS, Jeong MJ, Kim KW, Lee SK, Park SC. 2014a. Phenotyping of rice in salt stress environment using high-throughput infra-red imaging. Acta Botanica Croatica 73: 149-158.

Siddiqui ZS, Cho JI, Kwon TR, Ahn BO, Lee KS, Jeong MJ, Ryu TH, Lee SK, Park SC, Park SH. 2014b. Physiological mechanism of drought tolerance in transgenic rice plants expressing Capsicum annuum methionine sulfoxide reductase B2 (CaMsrB2) gene. Acta Physiologia Plantarum 36: 1143-1153.

Siddiqui ZS. 2013. Effects of double stress on antioxidant enzyme activity in Vigna radiata (L.) Wilczek. Acta Botanica Croatica 72: 145-156.

Siddiqui ZS, Khan MA, Kim BG, Huang JS, Kwon TR. 2008. Physiological response of Brassica napus genotypes in combined stress. Plant Stress 2: 78-83.

Silveira JAG, Silva EN, Ferreira-Silva SL, ViégasRA. 2012. Physiological mechanisms involved with salt and drought tolerance in Jatropha curcas plants. In N. Carels et al. (eds.), Jatropha, Challenges for a New Energy Crop: Volume 1: 125 Farming, Economics and Biofuel. DOI 10.1007/978-1-4614-4806-8_7.

Sirault XRR, James RA, Furbank RT. 2009. A new screening method for osmotic component of salinity tolerance in cereals using infra-red thermography. Functional Plant Biology 36: 970-977.

Stepien P, Klobus G. 2006. Water relations and photosynthesis in Cucumis sativus L. leaves under salt stress. Biologia Plantarum 50: 610-616.

Woo N, Badger MR, Pogoson B. 2008. A rapid non-invasive procedure for quantitative assessment of drought survival using chlorophyll fluorescence. Plant Methods 4: 27.

Zia S, Spohrer K, Wenyoung D, Spreer W, Romano G, Xiongkui H, Mller J. 2011. Monitoring physiological responses to water stress in two maize varieties by infrared thermography. International Journal of Agricultural and Biological Engineering 4: 7-15. 